\title{
DOES SOCIAL REMITTANCE TAKE PLACE AMONG INDONESIAN PLANTATION WORKERS IN MALAYSIA?
}

\author{
${ }^{1}$ Linda A. Lumayag \& ${ }^{2}$ Rahim Mohd Sail \\ ${ }^{1}$ Department of Southeast Asian Studies, University of Malaya \\ 2Universiti Putra Malaysia \\ (llumayag@um.edu.my)
}

\begin{abstract}
Diffusion of new ideas via international migration is an interesting phenomenon if one wants to study social change. This is a case study that examines the role of migration in understanding diffusion and transmission of skills and knowledge into the home country of foreign workers. It looks at a specific group of migrant workers in the plantation sector in Malaysia and how their position as Indonesian migrants facilitates and encourages transmission of cultural elements to their home country. It means examining their experiences in Malaysia to know the extent to which they can be agents in the diffusion of new skills and knowledge in the local community. Drawn from a qualitative study in 2010, both interview and focus group discussion were conducted among Indonesian workers in oil palm plantation in Johor, in the southern part of Malaysia. The study finds that social remittance is only realistic and feasible when workers have the financial means to possibly carry out the new ideas and skills they have observed, acquired and learned. These ideas and skills may also be very limited to the kind of exposure they have experienced while living in Malaysia considering the limitations they encountered. Actual application of ideas and skills they have acquired and remitted to their home country still largely depends on the availability of finances and the migrant workers agency when they will eventually return to Indonesia. Diffusion can only be realized when a 'friendly' environment is available for the diffusion of new ideas.
\end{abstract}

Keywords: Indonesian workers, Malaysia, social remittance, plantation work 


\section{Introduction}

This paper takes the view that migration does not always necessarily lead to change. By change we take a very generic understanding of a shift from "what is traditional" to "what is modern". It re-interprets the view by Alejandro Portes (2010) that changes generated by migration only yield marginal modifications of the social order, and leaving the deep elements of values and social structure substantially unchanged - and sometimes even buttressing the fundamental constitutive elements of society (Van Hear, 2010:1532). While Portes qualifies his position that social change is hardly felt especially in the host country, we argue that social change, in any form, nature or structure takes place in both sending and receiving countries. It is thought that the development of new ideas, behavior and skills would support and promote greater or broader development in migrants and their families' relationships as shown in micro studies on migration. There are also observations that show that effects of migration are mixed. O'neil (2003), for instance, suggests that migration does not lead to structural changes needed for long-term development and may actually delay them. This argument states that, much like a natural resource windfall, migration may raise incomes without boosting know-how and institutional capacity, while creating perverse incentives that lead to unsustainable family economies. Nevertheless, while this may be true to some extent, there are qualitative changes that are taking place at the level of the migrants such as in the acquisition of technical knowledge and practices while being transnational. For example, an observation of Kompas, an influential newspaper in Indonesia, reveals that in one situation a group of female exmigrants from various districts organized themselves to exchange knowledge, skills and money to support and improve their communities (Kompas, 2008). This may just be one of the many developments occurring in the community which needs to be explored and studied.

This present paper clarifies the argument that social remittances in the form of ideas, skills and practices provide impetus for social change. Following Levitt (1996) social remittances are what we call the nonmonetary elements that are transmitted to the home country in whatever means. Traditionally, the understanding of remittances is solely focused on monetary transactions, with a plethora of literature on the positive effects of migration is demonstrated in the way migrants are able to provide financial assistance to the households, local community and the national economy. Remittances are among the most tangible links between migration and development. Monetary remittances bring about social change in the country of origin of migrant workers as shown in the studies of Levitt (1996). According to the World Bank, migrants sent $\$ 338$ billion to their homelands in 2008 (Levitt \& Deepak, 2010). A few countries in Asia that heavily 
rely on the monthly dollar remittances are the Bangladesh, Philippines and Indonesia (Che Hashim Hassan, 2009).

On the other hand, remittance in the form of ideas, skills and practices is not well-addressed in the literature. It is an understudied, important piece of the migration-development nexus (Levitt \& Deepak, 2010) but rarely given its fair space in the corpus of migration studies. Following Levitt (2001), social remittances are ideas, know-how, practices, and skills that shape migrants from the developing world. Ideas, resources and discourses influence and transform social identities, households, and power relationships and these also circulate within transnational networks (Huan et al., 2003, as cited in Ramirez et al., 2004). Just as the financial remittances operate, as referenced in how it supports the economy at the macro level, and how they support personal consumption, education and lifestyle of migrants and their families at the micro level, social remittances do have structures that sustain the transfer of ideas, resources and cultural practices. Social remittances are transferred by migrants and travelers or they are exchanged by letter or other forms of communication, including by phone, fax, the internet or video, emails, letters and blogs (Levitt \& Deepak, 2010; Levitt, 1996). That social aspects of remittance are transferred by virtue of a medium is important. It can mean migrants bring the idea back to the sending country themselves or through an intermediary like letters and pictures. Social remittances affect family relations, gender roles, class and race identity, political, economic and religious participation (Sorensen, 2004) and this is evident in the way migrants are able to influence the household, at the least, to understand certain issues differently. According to Levitt (2001), social remittances are locallevel counterpart to macro-level global monetary and cultural flows, although they are the key to understanding how migration modifies the lives of those who remain behind. Yeoh (2005) suggests that keeping in regular contact with transnational kin and the sending of remittances and cultural products are motivated not so much by economic reasons but by the need to maintain social and cultural norms. The Global Equity Initiative (GEI) based in Harvard University suggests that social remittances are catalysts for democratization, transparency and accountability (GEI, 2003). This is true especially when migrants have wider access to the news and print media aside from their immersion in the culture of the host country. Interestingly, how some ideas and practices are remolded in receiving countries, the mechanisms by which they are sent back to sending communities, and the role they play in transforming sending-country social and political life (Levitt, 1998) could be very significant. For example, Peggy Levitt's (1996) study of Dominican immigrants in Boston as host community and Dominican Republic as the sending country, examines the social connections between these two communities arguing that physical mobility in immigration does not mean "forgetting" the immigrants village of origin and instead found a 
continuing social and economic relations, practices, ideas and behavior that both positively and negatively influence the two communities. How has this transmission of social behavior and practices been possible and which transmission varies from culture, community and identity? Could such practices and behavior bring about tangible and intangible forms of development in the immigrants' community and therefore create social change?

The conceptual understanding of social remittance may be seen in the idea of transnationalism (Basch, Glick Schiller \& Szanton Blanc, 1994) where the existence of significant networks are maintained across borders and these social ties can be familial, institutional or religious that can provide another dimension if we look at diffusion of new ideas. It implies the use of networks to enable transmission of knowledge and skills. But then again, the extent to which ideas and other cultural elements travel beyond the so-called nation-states may depend on a lot of things. For instance, there may be technological gadgets to aid in communication but it remains to be seen what these "stories" they share across the border. Do they share about ideas related to work with the hope that family members will adopt these ideas, or do they talk about specific family issues only?

So how is social remittance transferred? Conceptually, a prerequisite to the transmission of social remittance is financial remittance. It is impossible to see transmission of social ideas, skills or knowledge on technology transfer without the aid of financial resource to begin with. Moreover, the process of social remittance is put to perfect fruition when temporary migrant workers return home to apply the necessary skills and knowledge on new technology they have learned while working outside their national borders. While we reckon that social remittances can be transferred conveniently since transnational ties allow this, one needs to explore the processes upon which the transmission of social remittance are restricted or hampered. Identifying the factors that preclude migrants from transmitting to their home country is critical in our understanding of social remittance rather than subconsciously believe that the transmission is not without any constraints. Identifying these constraints too may engender new ways of analyzing the process of transmission specific to certain cultures and the political and economic conditions of migrants live and work.

The objective of this paper is to explore the role of temporary migrants as agents of innovation through the transfer of skills and knowledge as they work in an oil palm plantation in Malaysia. Temporary migrants refer to circular migrants who continually go in and out of Malaysia for a certain period of time. It also examines the challenges or issues they experience in the transmission of skills and knowledge. This study is focused on Indonesian oil palm workers in Johor in Peninsular Malaysia who have been working in the plantation for at least two years. The focus of this research is to understand the processes that affect or influence the transfer of ideas and knowledge related to agriculture. Significantly 
this paper could contribute to the whole issue of whether the transmission of social remittances is a natural course of event in international migration. Levitt (1996) seems to suggest that social remittance is an offshoot of migration. However, the experience of Indonesian plantation workers seems to show otherwise.

\section{Research Methodology}

This study was conducted on Indonesian migrant workers in an oil palm plantation in Johor, the southern state of Malaysia in 2010. All informants came from the provinces of Lombok, West Java and Central Java. Fifteen (15) migrant workers were individually interviewed and a focus-group discussion was held with a group of five workers. Interviews were recorded and later transcribed and categorized into themes. The different themes that came out of the interview and discussion are presented in this paper. Primary data were substantiated with secondary information such as newspaper articles and government reports. The selection of informants was based on purposive sampling in the sense that the research team wanted to identify specific category of migrant workers and in specific sector of the Malaysian economy.

The plantation manager and his assistant were also interviewed to understand their views on engaging in foreign workers from Indonesia. One limitation in this research study is the difficulty of getting access to documented plantation workers without the knowledge of the plantation management, hence only fifteen were willing to share their experiences as oil palm workers. This study acknowledges the fact that the issue on social remittance takes a different route especially with regard to other categories of workers such as domestic workers or, maybe, migrants in the entertainment or construction industry.

\section{Data and Discussion}

In this section, I start by providing a brief description of oil palm plantation $X$ and its workers. Next, I describe the kind of work that migrants do, their understanding about the expectations of being migrant workers, and also their living conditions in the plantation that somehow affect their prospects of the future.

\section{Oil Palm Plantation and Its Workers}

The plantation involved in this study is one of the oldest oil palm plantations in Johor, Malaysia and prides itself as a good employer to about four hundred plantation workers, of which three hundred workers are Indonesians and 100 are local workers. The plantation covers about 4000 acres, managed by a plantation manager and his assistant. The manager opines that his workers are legally hired 
through an employment agency in Kuala Lumpur. During the FGD, however, the respondents were tight-lipped to share their legal status and everyone informed the research team that they all have valid documents. Nonetheless, at the time the interview was conducted, not a single worker was holding his passport and they further alleged that their passports were kept by the management. According to the manager, the management prefers unmarried men, though married workers are also welcomed. However, of the 300 or so Indonesian workers assigned in various stages and areas of plantation work, only a few are single and young. The average age of workers is 28 years old, the youngest is 24 and the oldest 46 . Most of the workers have at least a year stay in Malaysia. Most of the ten informants were married with young children back in Indonesia. Most of the workers have low level of education, which is in tandem with the observation of Abdul-Rashid Abdul Aziz (2001) and Sukamdi, Haris and Brownlee (1998) that, Indonesian workers in Malaysia have usually low level of education. The management provides free housing and medical facility while payment of water and electricity is shared equally by plantation management and worker.

Workers come mainly from West Java, Lombok and Central Java and speak different dialects, although Bahasa Indonesia is the unifying language when they are at work. The plantation management thinks it is much easier to "manage" when workers come from the same village or ethnic group, presumably because when they speak the same language they can better understand one another. The workers however shared that language is not a problem as they use Bahasa Indonesia when talking to others outside their ethnic group. The plantation manager relates that a team of interviewers went to Indonesia and interviewed young and able-bodied men from the village with the idea that they would remain here without feeling a "loss" and concentrate on their jobs. Indonesian workers are driven by their desire to earn money for their families. According to the married workers, on the average they send RM400 every two months and with annual remittance of 8 million Indonesian rupiah. Most of the workers have come to Malaysia by several means both legal and illegal. They paid between RM1200 and RM2000 to the middlemen from money borrowed from family members or relatives or both.

\section{Work, Networks and Money}

For most of the Indonesian workers in this study, they said that plantation work is 'common' work. Five workers had done harvesting and pruning both in Indonesia and Malaysia plantations prior to their present work. It is because of their prior experiences that they were hired. Most of the workers value discipline and strict working habits at the plantation. They opined that "we have to work really hard in order to reach the daily quota, and without hard work, the daily quota is difficult to reach." For instance, the daily quota for a harvester is $2000 \mathrm{~kg}$. Discipline 
includes waking up early in the morning and ensuring they will have more time to work. If the worker cannot reach the quota for that day, then his daily rate will be much lower. The worker therefore needs to meet the quota and even exceed it so that the take home pay will be more. Harvesting is the most tedious and labourious type of work in the oil palm plantation and it is paid the highest. There are workers who want to be harvesters so that they get more pay, however, this task needs more skill and not anyone can do it. The handling of the very long pole made of steel and simultaneously timing it with the worker's footwork demands dexterity and footwork. Only few workers can somehow perfect this skill. For some who cannot cope with this particular task, they retreat to a much easier plantation work such as carrying of oil palm from the farm to the repository area.

One interesting finding in this research is skill mismatch. Though some of the workers said they already have prior experience in the oil palm estates in Malaysia, it is inconceivable that their experience and knowledge on new technology they have acquired while working in Malaysia cannot be put to good use when they eventually return to their respective communities. What accounts for this mismatch is that they come from a rice-farming (sawah) community, while in Malaysia they work in the plantation (ladang) sector. This means that they may have acquired the work skills in the plantation but in terms of applying or using these skills later on in life, the possibility is slim or perhaps even remote. The best option for them would be to work in the oil palm plantations in the Kalimantan region in Indonesia.

Across countries and cultures in Asia (e.g. Philippines) acquiring education to improve one's economic condition is given emphasis both within and outside the family setting. Filipino overseas domestic workers, for instance, consider education of children as a major justification for working abroad. However, at least for the workers in the plantation worker who have little children, they seem to be skeptical about education saying "even when you get high education, you will still end up as worker in the plantation which does not need education at all." It is also shared that Indonesian women do not need to go to school because they will also end up as domestic workers in other countries anyway (see Tharan (1993), for comparative observation). The globalization of work has resulted in the changing idea about education and this poses a challenge to the pemikiran simpit (narrow-mindedness) of plantation workers towards education. How would this attitude influence the future of the workers' children and their families is rather unclear.

Networks of migrants begin before they leave their villages through the circle of friends, relatives and acquaintances who share personal narratives or accounts of their experiences and observations while abroad. In this study, three of the workers knew each other before coming to Malaysia. In fact, they came from the same village and went through the same process which include going to the 
same agent for referral and other related matters. There are tendencies that members of the family migrate for work in the same country such as, in this case, Malaysia. In addition, both Malaysia and Indonesia share vast coastline borders and this has strong push factor from the Indonesia side to find employment in Malaysia. When there is a weak link between access to formal structures that offer services related to foreign deployment and access to work, Indonesian workers readily adopt illegal networks in order to realize their migration plan (Sukamdi, Haris \& Brownlee, 1998).

Within the plantation environment, workers share common needs and concerns. The strategic plan of plantation management to bring in workers from three different districts /areas in Indonesia is reflective of subtle labor control i.e. to eliminate group or ethnic clashes and for easy control compared workers from different ethnic affiliations. The management also share the view that to recruit two different ethnic groups may not be strategic for fear of labor problems and disputes that may arise between two conflicting ethnic groups. The management cannot afford to disturb the work rhythm in the plantation as it would result in loss of production, as one staff mentioned that it cannot afford to delay the process of production because everything is perfectly cadenced right from the recruitment of workers to the harvesting of the crop. A "re-tribalisation" of workers within the plantation environment is noted, as workers get to know more about the life of another worker, his wife and children and everyone. While they were identified as workers coming from Lombok district, for example, the moment they are placed in the plantation, they are seldom associated by their own group but identified themselves as workers from Indonesia. There seems to be a very strong sense of identity among the workers, and as shared by one worker from Central Java, "that the life story of one worker becomes almost the life story of another". Sharing of the same problems back home, the longing to be with loved ones, and how much money workers could remit to Indonesia are three common topics of discussion.

In 2006, Indonesian migrant remittances added approximately $\mathrm{Rp} 61$ trillion (US\$ 6.7 billion) (USD 1 is equivalent to 9,567.00 Indonesian rupiah) to the national coffers, second only to oil and gas industry in terms of foreign exchange contribution to the national economy. With this amount, it can feed about 30 million people in Indonesia, according to the National Board of Indonesian Migrant Worker Placement and Protection (Depnakertrans, 2007 as cited in Rusdiana and Saidi, 2008:163). Savings in this study refers to the money workers have saved for the use of their families in Indonesia. The workers who were interviewed were diligent financial remitters, sending as high as RM400 a month. The money goes to the household expenses, education of children, improvement of the house, start a micro business, and perhaps, a little amount to keep aside as savings, as Mantra's (1999) study also suggests. The financial remittance basically is a survival strategy since this is the only cash resource for the family. If ever there 
may be some savings, this may only last for a month or so and then go back to being without cash reserve again. So, migration for work is rather just a household or family strategy and it is safe to say that with small financial remittances from abroad, families are able to sustain its financial as well as other needs. Observations are abundant that one can exactly know which country a family/household member migrant is working by the quality of house/shelter a migrant worker provides in the village.

\section{Social Isolation}

The oil palm plantation is located about six (6) kilometers from the town center. A 'ghetto' - like existence reflects a life that is both physically and socially isolated from the rest of the community. Life in the plantation is life in isolation where people are not free to come in and out of the plantation area, except when necessary. They live in a housing provided by the management with access to water and electricity. Some own motorbikes to go to the mosque for their Friday prayer but most often they stay in the housing area or work in the ladang (field). The passports of workers are kept by the management and therefore it is difficult to make public transactions, for example, sending money through the banks as one needs it to present his passport. In this case, they would rather use the assistance of middlemen to remit their salary to Indonesia. One way to learn ideas about how other things work is through observation and actual experience. It would be more interesting to know how workers view their relationship with the outside world and how this influences their perception of the environment. The passport issue indeed sets limit to workers' socialization and failure to possess one invites another form of dispiritedness i.e. the likelihood that they will be harassed by police authorities or RELA (Ikatan Relawan Rakyat Malaysia) or Volunteers of Malaysian people. Worker control is through physical isolation to deter workers from forming networks of connections outside the plantation. This will therefore stop them from being 'courted' or 'pinched' by potential employers. Though the worker's passport may not be in his possession yet, it will stop the worker from leaving if better wage arrangement is available. This observation is validated by the plantation manager when he says, 'workers having less access to the outside world, and therefore having less friends, the probability of leaving the plantation to work in another sector for higher wages is very slim'. In another study (Samsuddin, 2003), it was revealed that plantation workers are attracted to the lure of city life and also to get higher wages, the only way to go there is to work in construction industry. Plantations which are located in the hinterlands of Malaysia face the problem of supply of workers who cannot withstand isolation. At any opportunity therefore, plantation workers would rather work in the construction sector because aside from higher wages, they have space to mingle with others. 


\section{Limitations in Transmission of Skills and Knowledge}

Indonesia is the main supplier of huge manpower for Malaysia's economy. Malaysia is also known to be a prime mover in promoting new technology especially on new high-yielding varieties and cultural practices, new ways of harvesting, management of raw materials, utilization of the product among others. The exposure of Indonesian workers - most of them unskilled - to new technology could propel modernization in agriculture (Castles, 2000) in Indonesia as ideas and practices are shared across the borders. Estate industries in Malaysia rely heavily on Indonesian workers to work for the following tasks: weeding, pruning, manuring, pest control, etc. Indonesian workers who have been working in the plantation industry are potential transmitters of ideas and technical skills to their relatives and family members back home. Both Indonesia and Malaysia share similar climate, soil types, rainfall patterns, and even cultural practices. This similarity could be a good material for adoption of new technology that migrant workers would eventually apply during or after their employment in Malaysia. Given the period of time and workers' exposure to the technical know-how in "nurturing" plantation, there is ample opportunity to learn certain skills hopefully to be adopted to their own community/locality when they return. An estate worker shares that as when he returns he would like to invest his money on a piece of land. For some migrants, one of the motivations to save money is to buy a piece of land for agricultural purposes or to build a house, for his family. In this sense, their exposure in the new ways of agricultural production or land cultivation will influence their future planning. The thousands of Indonesian workers in oil palm plantations could be called change agents and could well create a multiplier effect the moment they begin to apply new forms of technology in Indonesia, which they have acquired while working in Malaysia. However, this depends on the following considerations:

The extent to which technology is transferred to Indonesia lies on whether these migrant workers have access to the various ways of remitting these skills and ideas. For instance, do migrant workers have the opportunity to write letters to their family members, make phone calls, send text messages, or return home regularly? Successful social remittance is viable when they are workers with valid documents, meaning they are employed legally by estate owners since documented workers can take their vacation leave once in every two years, or make phone calls as they wish, at nearby 'Wartel' telecom centers (at the time this fieldwork was conducted, the use/ownership of mobile phones was not a prominent feature), or send letters to the family members. That ideas and knowledge can then be transmitted in as many ways such as those mentioned, as a natural consequence. In a way, transmission will be a course of event, in its purest form and shape when workers do not face serious constraints in the way they want the social transfer to be done. 
Pertinent issue is the problem of undocumented workers especially from the Indonesian community. The high turnover of Indonesian workers caused by documentation problems and when there is a much higher offer in the construction sector that they find more attractive. Undocumented workers (e.g. without permit, no passport, or passport has expired) find it more difficult to go about transmitting social remittance because of their vulnerability to police harassment or detention. At this point, the position of undocumented workers limits or restricts their opportunity to transmit ideas and information to their family members. There may be a modicum of transmission but that is not quite easy, and risk is always there. Estate owners, though they want Indonesian workers to work in the plantation, still prefer undocumented workers since they submit to low wage etc. Bogus and unscrupulous employment agents from both sides of the border who fleece migrant workers from both sides of the border are one of those responsible for producing tens of thousands of illegal or undocumented Indonesia workers in Malaysia (Jones, 2000).

Definitely, the varied experiences of plantation workers in Malaysia have left traces of influences on their expectations and prospects. Firstly, the diffusion of ideas and practices are shared not only within the social networks they have formed in Malaysia but also to their families, by phone and letters. In the sense, diffusion of ideas to the family members is aided by different social networks within the migrant's community and the networks of so-called migrant beneficiaries. In the Philippines, the dynamic social networks within the country could well influence the behavior, ideas and practices of those who have no opportunity to go abroad. As Levitt (1999) contends, networks within the field connect people with no direct transborder connections to those who have such connections. Moreover, networks can consist of either strong or weak ties that connect persons who maintain transnational relationships with those who do not but who are indirectly influenced by flows of ideas, objects, and social remittances within their field of social relations. However, it cannot be assumed that those who are directly connected are more transnationally active (Levitt \& Schiller, 2004).

Secondly, the acquisition of new knowledge, skills and ideas is dependent on the extent temporary migrants are "welcome" by Malaysia. It is argued that their opportunity to meet with other members of the Malaysian public, other than the employers and their immediate family members, is when they enjoy the weekly day-off, because that is the only time they could form social networks outside the workplace away from the watchful eyes of the employers. For plantation workers, they are placed in highly isolated places and contact with local people other than their "bosses" is limited. It is limited in the sense that while they may meet on Friday prayers, such meeting is too short to allow for a deeper level of interaction with other workers. Establishing contact with the local people allows migrants to learn and acquire social ideas that they feel worth adopting, as 
Hassinger (1951, cited in Rogers and Shoemaker, 1971) contends that individuals will seldom expose themselves to messages about an innovation unless they first feel a need for the innovation messages. There will be little effect of such exposure unless the individual perceives the innovation as relevant to his needs and greater portions of savings remain in the host country.

Thirdly, transmission and, eventually, adoption of social remittance is dependent on financial transfer. Financial remittance is important in order to initiate new ventures or projects or to apply new technologies. It is in this aspect that migrant workers or their families' access to capital in the home country that is really important so that they can realise their plans. Government agencies responsible in providing initial capital for business, providing supervision and technical expertise could be tapped up to promote migrant projects. Mantra (1999) in fact suggests that remittance carried back home by the return migrants to their areas of origin are not large, so much so that they keep on returning to Malaysia to work.

\section{Conclusion}

Social remittance in the form of ideas, practices or skills is an impetus for social change. However, a necessary requirement in the transmission of social remittance is access to financial resources, just to be able to start a project or to introduce a new technology. Acquisition of new skills and knowledge would remain dormant if there is no available financial resource to start up a project. Transmission of social remittance is only made noble when it plows back financial returns/income rather than creating a whole new set of lifestyle that is not in tandem with cultural practices. Since the mode of transmission is quite restricted, social remittance would peak when migrant workers themselves return home and apply what they have learned - and practiced - while working in Malaysia. The transfer of knowledge and skills will be more pronounced when the individual migrant workers themselves put into practice what they have learned and acquired, provided that they have the financial means to do so with the support of local government agencies. Sharing of knowledge through the phone for instance, is something that is not happening. While the advancement in telecommunication as well as migrants' access to new gadgets may promote the transfer, it does not seem to be happening here. In a way, what these oil palm plantation workers usually share is the family well-being, health of parents and children, festivities and all. Rarely the discussions dwell on other things.

It is safe to say that plantation workers have least opportunity to transmit and practice the skills and knowledge they have acquired in Malaysia as this would imply spending high capital for investment. This is in contrast to domestic workers who may acquire new strategies or ideas in cooking or business to start a 
new phase of their life. Equally important is the legal status of migrant workers. Undocumented workers face a lot of limitations, not only on employment, but also on how to transmit social remittance because of their vulnerability to exploitation and abuse. They may not be able to go home when their contract expires and therefore decide to live in Malaysia despite their undocumented status. The possibility of putting new knowledge into practice will just remain a dream. Transmitting social remittances may be easy and fast for some migrant workers or it can be slow and difficult to others.

\section{References}

Asis. M.B. (1992). The overseas employment program policy. In Battistella, G. and Paganoni, H. (Eds.), Philippine Labor Migration.

Basch, L., N. Glick Schiller \& C. Szanton Blanc. (1994). Nations unbound: Transnational projects, postcolonial predicaments, and deterrioralised nationstates. Amsterdam: Gordon and Breach.

Carrasco, L. (2010). Transnational family life among Peruvian migrants in Chile: Multiple commitments and the role of social remittances. Journal of Comparative Family Studies, 41, 2.

Castles, S. (2000). Migration as a factor in social transformation in East Asia. Conference in Migration and Development. Princeton University, 4-6 May 2000.

Castles, S. (2010). Understanding global migration: A social transformation perspective. Journal of Ethnic and Migration Studies, 36, 10.

Che Hashim Hassan. (2009). Foreign labour in Malaysia: Trends, methods, impacts, problems and strategies to the solve the problems. JATI, 14.

Cholenwinski, R. (2005). Protecting migrant workers in a globalised world. Migration Information Source. March 1, 2005.

Economic and Social Commission for Asia and the Pacific (ESCAP). (2001). International migration: An emerging opportunity for the socio-economic development of the ESCAP region. Social Policy Paper No.6.

Gabbarot, M. \& Clarke, C. (2010). Social capital, migration and development in the Valleys Centrales of Oaxaca, Mexico: Non-migrants and communities of origin matter. Bulletin of Latin American Research, 29, 2.

Gamburd, M.R. (2000). The kitchen spoon's handle: Transnational and Sri Lanka's migrants housemaids. Ithaca and London: University Press.

Global Equity Initiative, GEI (2003). Diaspora philanthropy: Perspectives on India and China. Harvard University: Global Equity Initiative.

Hugo, G. (1998). The demographic underpinnings of current and future international migration in Asia. Asia and Pacific Migration Journal, 7.

Hugo, G. (2007). Indonesia's Labor Looks Abroad. Retrieved July 28, 2011, from 
http://www.migrationinformation.org/Profiles/display.cfm

Jones, S. (2000). Making money off migrants: The Indonesian exodus to Malaysia. Hong Kong: Asia 200 Ltd.

Kompas. (10 March 2008).

Levitt, P. (1996). Social remittances: A conceptual tool for understanding migration and development. Retrieved from, ww.hsph.harvard.edu/hcpds/wpweb/96_04.pdf

Levitt, P. (2001). The transnational villagers. Berkeley and Los Angeles: University of California Press.

Levitt, P. (2003). Diaspora philanthropy. Perspectives on India and China. Harvard University. Workshop on Global Equity Initiative, 7-8 May, 2003.

Levitt, P. \& Schiller, N. (2004). Conceptualizing simultaneity: A transnational social field perspective on society. International Migration Review, 38, 3.

Levitt, P. \& Deepak Lamba-Nieves. (2010). It's not just about the economy, stupid Social Remittances revisited. Migration Information Source.

Mantra, I.B. (1999). Illegal Indonesian labor movement from Lombok to Malaysia. Asia Pacific Viewpoint, 40, 1.

Nauck, B. (2001). Social capital, intergenerational transmission and intercultural contact in immigrant families. Journal of Comparative Family Studies, 32, 4.

Portes, A. (2010). Migration and social change: some conceptual reflections. Journal of Ethnic and Migration Studies, 36, 10.

Ramirez, C., M. Garcia Dominguez \& J. Miguez Morais. (2004). Developing a framework to understand the relationships between migration, gender, remittances and development. United Nations International Research and Training Institute for the Advancement of Women.

Rogers, E. M. \& Shoemaker, F. F. (1971). Communication of innovations: A crosscultural approach. New York Free Press: Department of Communication. Michigan State University, East Lansing.

Rusdiana, D. \& Saidi, Z. (2008). Diaspora giving: An agent of change in Asia Pacific communities? Asia Pacific Philanthropy Consortium.

Russell, S. (2003). Migration and development: Reframing the international policy agenda. Migration Information Source, June 1, 2003.

Semyonov, M. (2005). Gender gaps: Sources of earnings inequality in 20 countries. American Sociological Review, 70, 6.

Sorensen, N.N. (2004). Migrant transfers as a development tool. DIIS Working Paper 16. Retrieved from, http://www.diis.dk/graphics/Publications/WP2004/nns_development_dim ension.pdf

Sukamdi, Abdul Haris \& Brownlee, P. (1998) (Eds.). Labor migration in Indonesia: Policies and practices. Population Studies Center Gadjah Mada University. Asia-Pacific Migration Research Network. 
Taylor, E. (1999). The new economics of labor migration and the role of remittances in the migration process. International Migration, 37, 1, 63-86.

Tharan, C. (1993). Filipino domestic workers in Malaysia: Causes, mechanisms and consequences. Proceedings of the International Colloquium "Migration, Development and Gender in the ASEAN Region". Kuala Lumpur: Population Studies Unit, Faculty of Economics and Administration, University of Malaya.

Van Hear, Nicholas. (2010). Theories of migration and social change. Journal of Ethnic and Migration Studies. 36, 10.

Waters, J. (2003). Flexible citizens? Transnationalism and citizenship in amongst economic immigrants in Vancouver. The Canadian Geographer, 47, 3.

Yeoh, B. (2005). Remittances, savings, and policy formation in pacific island states: Discourses on migration and development, Asia Pacific Migration Journal, 14, 1-2. 